\title{
Resistance spot welding of dissimilar alloys 1008 low carbon steel- 5052 aluminum alloy
}

\author{
Mohammad Jameel Zedan ${ }^{+*}$ and Qasim M. Doos ${ }^{\dagger}$ \\ †Department of Mechanical Engineering, University of Baghdad, Baghdad, Iraq \\ Received 09 Jan 2018, Accepted 10 March 2018, Available online 19 March 2018, Vol.8, No.2 (March/April 2018)
}

\begin{abstract}
The resistance spot welding is adopted to joint dissimilar alloys such as aluminum alloy 5052, and low carbon steel alloy 1008. In this work, the electrodes force 2100-2700 N, the welding current 7.5-10.5 KA, and welding time 10-20 cycle have been used. The relationships between the three parameters have been studied. The maximum tensile shear load of the aluminum alloy 5052-low carbon steel 1008 joint has been found equal to $2860 \mathrm{~N}$ for weld nugget diameter of $9 \mathrm{~mm}$. The intermetallic compound layer (IMC) with 2-8 $\mu$ m thickness with tongue-like has been appeared adjacent to the 1008 low carbon steel side, whereas a needle-shaped IMC layer adjacent to the aluminum alloy 5052 side.
\end{abstract}

Keywords: Resistance spot welding, Dissimilar alloys welded joints, nugget diameter, Interfacial microstructure.

\section{Introduction}

The joining of dissimilar metals is desirable for some designing requirements. In the 1990s, the aluminum panels began to be used in car body due to the environmental issue and weight reduction (Carle \& Blount, 1999)(Barnes \& Pashby, 2000)(Sakurai, 2008)(Oikawa, Ohmiya, Yoshimura, \& Saitoh, 1999). Among many aluminum alloys, the automotive industry is used the 5XXX and 6XXX Al-alloys. So the 5052 alloy was chosen for its strain hardenable, and weldability (Davis, 2013).

In other side, car manufacturers preferred low carbon steels because the ease of panel forming from flat sheets. The suitable resistance welding technique (RSW) were very desired for mass production like car industry (Oikawa et al., 1999) (A. M. Al-Mukhtar, 2015). Therefore, the low carbon steel 1008 was chosen (Nikolaevich, Valerievich, Igorevich, Alexandrovich, \& Alexandrovich, 2014). As a technique for joining sheet metal components, RSW is much quicker than riveting, see Ref. (Briskham et al., 2006). The components being joined are not weakened since no holes are drilled in. Also, less skill is required, resulting in lower labor costs since the process is largely automated. Welding of aluminum alloys with steel alloys by resistance spot welding is a major challenge due to their different physical properties (Mathers, 2012).

Few researchers used RSW to join dissimilar materials of aluminum alloy and steel, see Refs. (Zhang,

*Corresponding author's ORCID ID: 0000-0001-5401-7172, DOI: https://doi.org/10.14741/ijcet/v.8.2.11
Qiu, Sun, \& Han, 2011),(Arghavani, Movahedi, \& Kokabi, 2016),(Chen et al., 2016)(Oikawa et al., 1999). They studied the effects of time, current, and electrode force on the mechanical properties and microstructures. In the current work, similar results have been obtained. The layer's form of $\mathrm{Fe}_{4} \mathrm{Al}_{13}$ or $\mathrm{FeAl}_{3}$ phase with needle-like is found beside the aluminum alloy. In addition, $\mathrm{Fe}_{2} \mathrm{Al}_{5}$ phase with lathlike beside the steel.

In this study, Aluminum alloy 5052 and low carbon steel 1008 were welded by resistance spot welding machine. The effects of welding parameters on the strength of the steel-aluminum alloy joints and welding nugget diameter were investigated. The interfacial microstructure and microrhardness of the welded area were studied.

\section{Experimental Procedure}

The materials used in the study were 1008 low carbon steel with thickness of $0.76 \mathrm{~mm}$ and 5052 aluminum alloy with thickness of $0.82 \mathrm{~mm}$. The chemical compositions of the used materials are listed in Table 1. The dissimilar samples were machined into the size of $(100 \times 25) \mathrm{mm}$, see Fig. 1 .

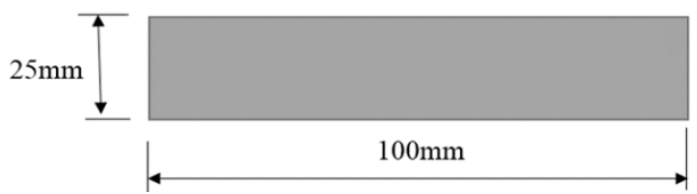

Fig. 1 Sheets size of low carbon steel and aluminum alloy samples 
The welding current 7.5 to $10.5 \mathrm{kA}$, time 10 to 20 cycles, and electrode force from 2100 to $2700 \mathrm{~N}$ have been used. The squeeze time and hold time was hold at 99 cycles. The used welding machine was S.I.P type PPV 50. The electrodes flat tip with diameter $11 \mathrm{~mm}$ was used. The samples were prepared by degreasing with acetone and grinding. Fig. 2 shows the sample dimensions and geometry.
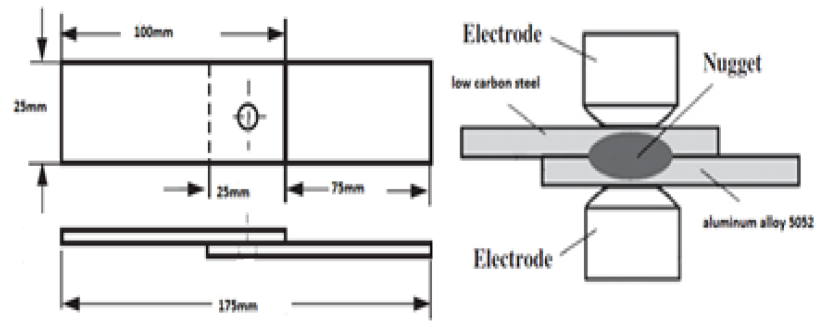

Fig. 2 Low carbon steel and aluminum alloy samples lap joint configuration

Table 1 Chemical composition of low carbon steel and aluminum alloy sheets

\begin{tabular}{|c|c|c|c|}
\hline $\begin{array}{c}\text { Chemical } \\
\text { compositions\% }\end{array}$ & $\begin{array}{c}\text { Low } \\
\text { carbon } \\
\text { steel 1008 }\end{array}$ & $\begin{array}{c}\text { Chemical } \\
\text { compositions\% }\end{array}$ & $\begin{array}{c}\text { Aluminum } \\
\text { alloy 5052 }\end{array}$ \\
\hline $\mathrm{C} \%$ & 0.049 & $\mathrm{Si} \%$ & 0.161 \\
\hline $\mathrm{Si} \%$ & 0.041 & $\mathrm{Fe} \%$ & 0.537 \\
\hline $\mathrm{Mn} \%$ & 0.197 & $\mathrm{Cu} \%$ & 0.025 \\
\hline $\mathrm{P} \%$ & 0.006 & $\mathrm{Mn} \%$ & 0.058 \\
\hline $\mathrm{S} \%$ & 0.003 & $\mathrm{Mg} \%$ & 2.31 \\
\hline $\mathrm{Cr} \%$ & 0.032 & $\mathrm{Cr} \%$ & 0.255 \\
\hline $\mathrm{Mo} \%$ & 0.004 & $\mathrm{Ni} \%$ & 0.007 \\
\hline $\mathrm{Ni} \%$ & 0.026 & $\mathrm{Ti} \%$ & 0.02 \\
\hline $\mathrm{Cu} \%$ & 0.11 & $\mathrm{~V} \%$ & 0.015 \\
\hline $\mathrm{V} \%$ & 0.001 & $\mathrm{Li} \%$ & 0.062 \\
\hline $\mathrm{Fe} \%$ & $\mathrm{Bal}$. & $\mathrm{Al} \%$ & $\mathrm{Bal}$. \\
\hline
\end{tabular}

\section{Results and discussion}

\subsection{Tensile force of RSW joint}

To determine the optimal parameters that give the best strength of the resistance spot welding; the tensile shear test is performed, see Refs. (A. M. Al-Mukhtar, 2015; A. M. Q. D. Al-Mukhtar \& Doos, 2013; A AlMukhtar, 2016; AM Al-Mukhtar \& Doos, 2013). Figures 3-5 show the relationship between the three factors and tensile force. The values of tensile test results increase significantly by increasing the electrode force $2100 \mathrm{~N}$ to $2700 \mathrm{~N}$, welding current 7.5 to $10.5 \mathrm{KA}$, and welding time 10 to 20 cycle. About $55 \%$ of the specimens were failed by interfacial failure mode, and $45 \%$ showing pullout failure mode. The failure starts from the heat affected zone (HAZ) on the aluminum alloy side, see Fig. 4. The failure mode from the HAZ and weld toe is very common. Therefore, fracturing life is considered for many joints from these regions, see Refs. (A. M. Al-Mukhtar, 2013; A. M. Al-Mukhtar, Biermann, Hübner, \& Henkel, 2011; AM Al-Mukhtar, 2013; Al Mukhtar, Biermann, Hübner, \& Henkel, 2013; Daws, Al-Douri, \& Al-Mukhtar, 2003)

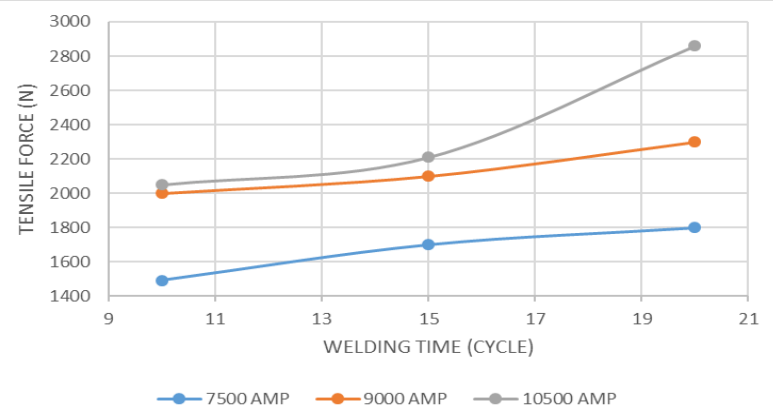

Fig. 3 The relationship between welding time and tensile force at electrode force $2700 \mathrm{~N}$

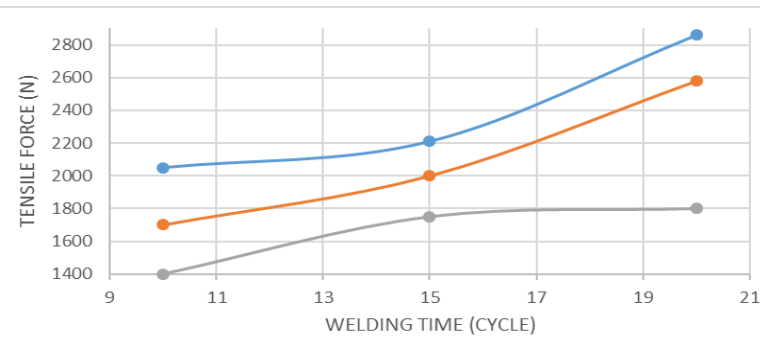

$\longrightarrow$ ELECTRODE FORCE (2700 N) —-ELECTRODE FORCE (2400 N) - ELECTRODE FORCE $(2100 \mathrm{~N})$

Fig. 4 The relationship between welding time and tensile force at welding current $10.5 \mathrm{KA}$

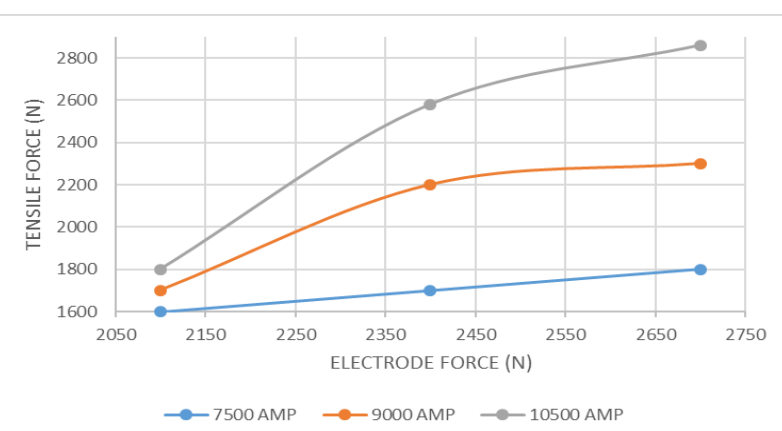

Fig. 5 The relationship between electrode force and tensile force at welding time 20 cycle

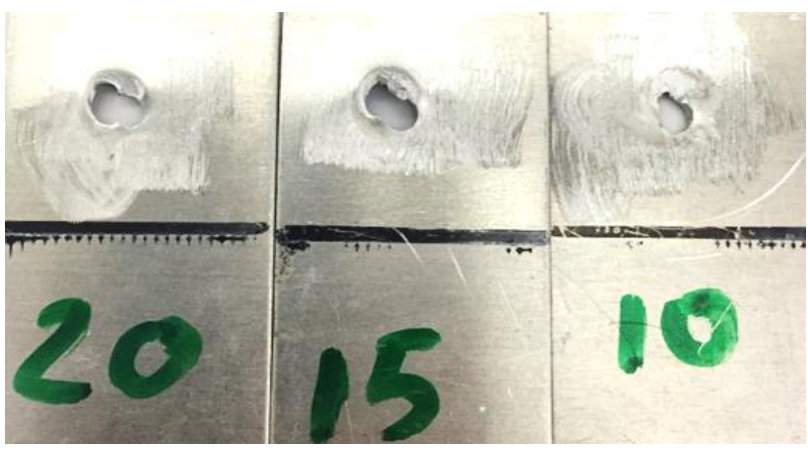

Fig. 6 Pullout failure mode from HAZ in the aluminum alloy side (current 10.5KA, electrode force $2100 \mathrm{~N}$, time 10,15 , and 20 cycle)

\subsection{Weld nugget diameter}

The weld nugget diameter is increasing with the increasing of welding time (10-20 cycle), current (7.5- 
$10.5 \mathrm{KA})$ and electrode force (2100-2700 N), see Figs 7, 8.

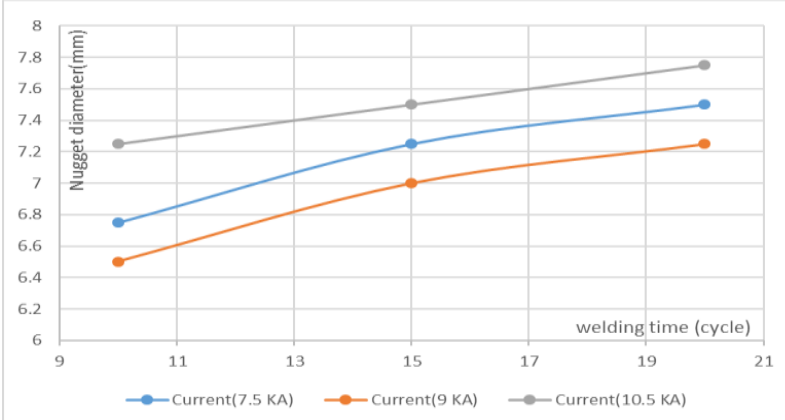

Fig. 7 The relationship between weld nugget diameter and welding time at electrode force $2700 \mathrm{~N}$

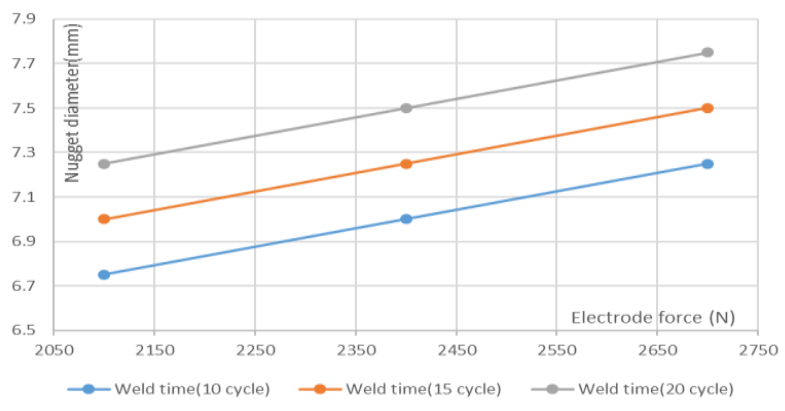

Fig. 8 The relationship between weld nugget diameter and electrode force welding current 10.5 KA

\subsection{Microhardness results}

The failure occurs in the HAZ from the aluminum side. Since this side the weakest area and the lowest microhardness, see Fig. 9.

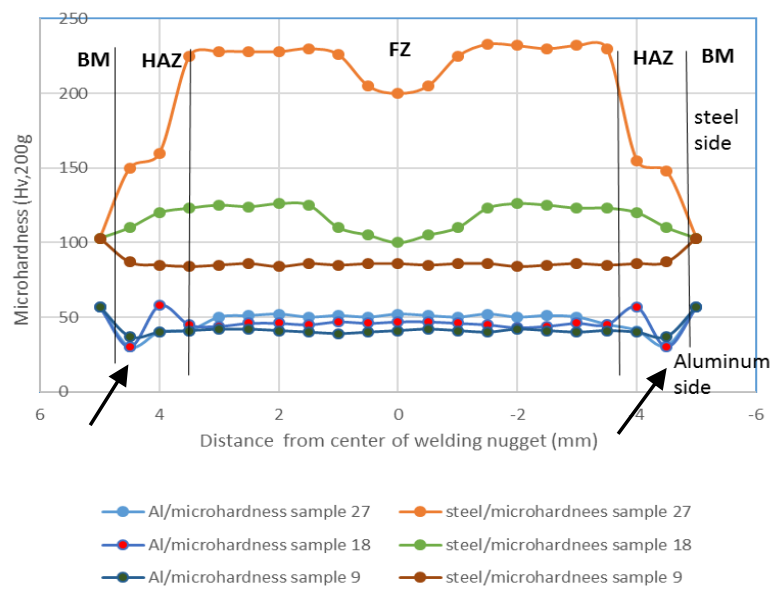

Fig. 9 The microhardness profiles in base metal, fusion zone and HAZ

\subsection{Interfacial microstructure results}

By using the scanning electron microscopy (SEM), the intermetallic compound (IMC) layer formed between the dissimilar alloys is shown in the Fig. 10. The obtained results showed that by increasing the welding current from 7.5-10.5 KA, the thickness of the intermetallic compound (IMC) layer decreases from 8$4 \mu \mathrm{m}$. Hence, the strength of the weld joint increases from $1800-2860$ N, see Fig. 10.

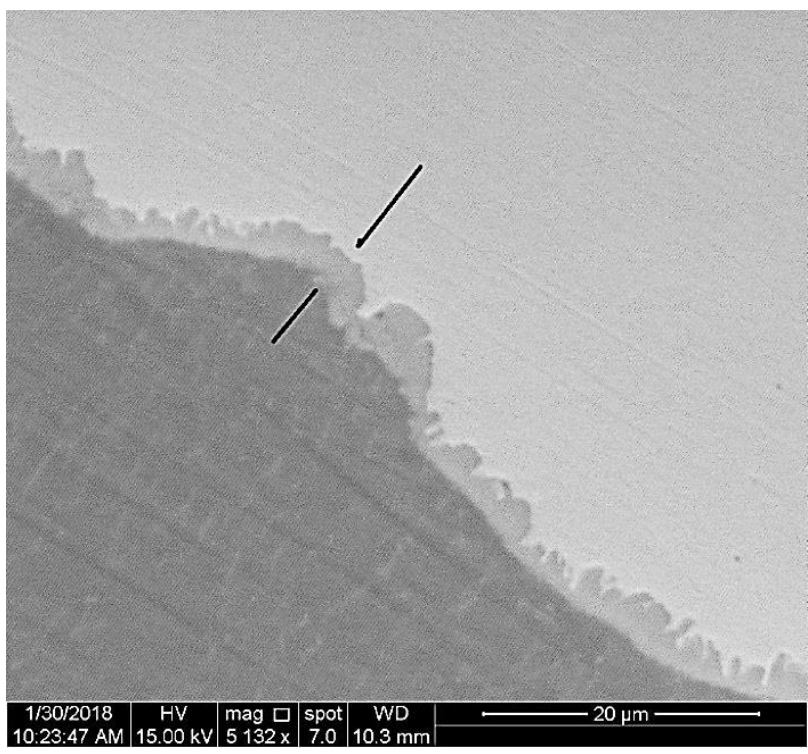

Fig. 10 The intermetallic compound layer (IMC) thickness between the dissimilar alloys

The discontinuous intermetallic compound layer (IMC) turns into a continuous layer when approaching the center of the weld nugget, see Fig. 11.

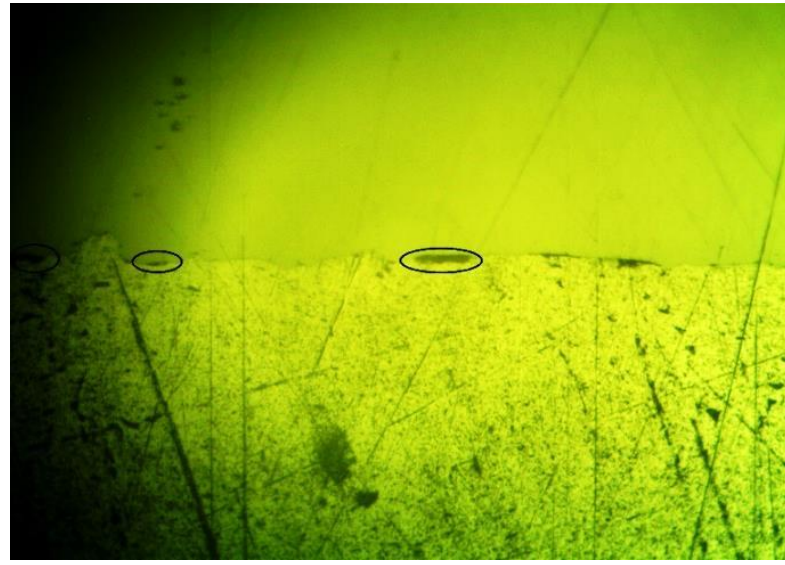

Fig. 11 The discontinuous intermetallic compound (IMC) layer

\section{Conclusions}

The tensile strength has been increased by increasing the electrode force, welding current, and the welding time. The optimum parameters are $2700 \mathrm{~N}, 10.5 \mathrm{KA}$, and 20 cycles, respectively, which gives the highest welding strength of $2860 \mathrm{~N}$.

The welding nugget diameter values are increased also by increasing the welding parameters. The largest weld area was obtained for the same parameters 2700 $\mathrm{N}, 10.5 \mathrm{KA}$, and 20 cycles, respectively, which gives weld nugget diameter of $7.75 \mathrm{~mm}$. Therefore, weld nugget diameter can be proportioned to the joint strength in the dissimilar alloys. The microstructure 
investigation was carried out. It shows that the increasing of weld current from 7.5-10.5 KA, the thickness of intermetalic compound layer (IMC) decreases from 8-4 $\mu \mathrm{m}$. Hence, the strength of the weld joint increases from 1800 to $2860 \mathrm{~N}$. The discontinuous intermetallic compound layer (IMC) turns into a continuous layer when approaching the center of the weld nugget.

\section{References}

Al-Mukhtar, A. (2013). Consideration of the residual stress distributions in fatigue crack growth calculations for assessing welded steel joints. Fatigue \& Fracture of Engineering Materials \&, 12060. https://doi.org/ $10.1111 /$ ffe. 12060

Al-Mukhtar, A. (2016). Review of Resistance Spot Welding Sheets: Processes and Failure Mode. In Advanced Engineering Forum (Vol. 17, pp. 31-57). Trans Tech Publ.

Al-Mukhtar, A., \& Doos, Q. (2013). Cracking Phenomenon in Spot Welded Joints of Austenitic Stainless Steel. Materials Sciences and Applications, 4(October), 656-662.

Al-Mukhtar, A. M. (2013). Residual Stresses and Stress Intensity Factor Calculations in T-Welded Joints. Journal of Failure Analysis and Prevention, 13(5), 619-623.

Al-Mukhtar, A. M. (2015). Spot Weldabaility Principles and Considerations. Südwestdeutscher Verlag Für Hochschulschriften Ag Co. Kg.

Al-Mukhtar, A. M., Biermann, H., Hübner, P., \& Henkel, S. (2011). The effect of weld profile and geometries of butt weld joints on fatigue life under cyclic tensile loading. Journal of Materials Engineering and Performance, 20(8), 1385-1391.

Al-Mukhtar, A. M. Q. D., \& Doos, Q. (2013). The Spot Weldability of Carbon Steel Sheet. Advances in Materials Science and Engineering, 2013. https://doi.org/10.1155/2013/146896

Al Mukhtar, A., Biermann, H., Hübner, P., \& Henkel, S. (2013). Fatigue crack propagation life calculation in welded joints. In CP2009.

Arghavani, M. R., Movahedi, M., \& Kokabi, A. H. (2016). Role of zinc layer in resistance spot welding of aluminium to steel. Materials and Design, 102, 106-114. https://doi.org/10.1016/j.matdes.2016.04.033
Barnes, T. A., \& Pashby, I. R. (2000). Joining techniques for aluminium spaceframes used in automobiles: Part I solid and liquid phase welding. Journal of Materials Processing Technology, 99(1), 62-71. https://doi.org/https://doi.org/10.1016/S0924-

0136(99)00367-2

Briskham, P., Blundell, N., Han, L., Hewitt, R., Young, K., \& Boomer, D. (2006). Comparison of self-pierce riveting, resistance spot welding and spot friction joining for aluminium automotive sheet. SAE Technical Paper.

Carle, D., \& Blount, G. (1999). The suitability of aluminium as an alternative material for car bodies. Materials \& Design 20(5), 267-272. https://doi.org/https:// doi.org/10.1016/S0261-3069(99)00003-5

Chen, J., Yuan, X., Hu, Z., Sun, C., Zhang, Y., \& Zhang, Y. (2016). Microstructure and mechanical properties of resistancespot-welded joints for A5052 aluminum alloy and DP 600 steel. Materials Characterization, 120, 45-52. https://doi.org/10.1016/j.matchar.2016.08.015

Davis, J. R. (2013). Aluminum and aluminum alloys.

Daws, K. M., Al-Douri, A.-K. A., \& Al-Mukhtar, A. M. (2003) Investigation of Some Welding Parameters in Resistance Spot Welding of Austenitic Stainleass Steel. College of Engineering Journal, Baghdad University, Iraq.

Mathers, G. (2012). The welding of Aluminium and its alloys. The effects of brief mindfulness intervention on acute pain experience: An examination of individual difference (Vol. 1). https://doi.org/10.1007/s13398-014-0173-7.2

Nikolaevich, S. A., Valerievich, A. A., Igorevich, G. A., Alexandrovich, S. A., \& Alexandrovich, S. M. (2014) Advanced materials of automobile bodies in volume production, (56), 1-27.

Oikawa, H., Ohmiya, S., Yoshimura, T., \& Saitoh, T. (1999). Resistance spot welding of steel and aluminium sheet using insert metal sheet. Science and Technology of Welding and Joining, 4(2), 80-88.

Sakurai, T. (2008). The latest trends in aluminium alloy sheets for automotive body panels. Kobelco Technology Review, 28, 22-28.

Zhang, W. H., Qiu, X. M., Sun, D. Q., \& Han, L. J. (2011). Effects of resistance spot welding parameters on microstructures and mechanical properties of dissimilar material joints of galvanised high strength steel and aluminium alloy. Science and Technology of Welding and Joining, 16(2), 153-161, https:// doi.org/10.1179/ 1362171810Y 0000000009 